\title{
Is cemented bipolar hemiarthroplasty a safe treatment for femoral neck fracture in elderly patients?
}

This article was published in the following Dove Press journal:

Clinical Interventions in Aging

26 June 2015

Number of times this article has been viewed

\author{
Emre Yurdakul' \\ Fatih Karaaslan ${ }^{2}$ \\ Murat Korkmaz \\ Fuat Duygulu ${ }^{3}$ \\ Ali Baktır ${ }^{4}$ \\ 'Department of Orthopedics and \\ Traumatology, Osmaniye State \\ Hospital, ${ }^{2}$ Department of Orthopedics \\ and Traumatology, Faculty of \\ Medicine, Bozok University, Yozgat, \\ ${ }^{3}$ Department of Orthopedics and \\ Traumatology, Kayseri Training \\ Hospital, ${ }^{4}$ Department of Orthopedics \\ and Traumatology, Modern Dünyam \\ Hospital, Kayseri, Turkey
}

Objectives: Controversy exists regarding the use of cement in hemiarthroplasty when treating a displaced femoral neck fracture in elderly patients. The primary hypothesis of this study was that the use of cement would afford better visual analog pain and activity scores in elderly patients.

Methods: This study included 133 patients over 65 years of age admitted to our clinics from 2006 to 2012 for the surgical treatment of a displaced femoral neck fracture. All patients were treated via hemiarthroplasty. The patients ( 66 males, 67 females; mean age: 78.16 years; range: 60-110 years) were followed-up regularly. All patients were divided into one of two groups: group A was treated with cement; and group B without. Both groups were compared in terms of preoperative features (demographics and associated diseases), pre- and postoperative complications, mortality rates, pain and activity levels, and hip scores. Hospitalization time, average surgical duration, and time from fracture to operation were also recorded. Mean follow-up duration was 30.9 (range: 5-51) months.

Results: We found no significant between-groups differences in terms of length of hospital stay, Harris Hip Score, complications, or follow-up mortality rates. Walking ability and pain scores were better in the cemented group in the early follow-up period. Duration of surgery and perioperative mortality rates were somewhat lower in the cementless group, but the difference was not statistically significant.

Conclusion: The use of cement during hip hemiarthroplasty in patients over 65 years of age had no negative impact on mortality or morbidity. Hemodynamic changes during cement application are important, but it is noteworthy that patients fitted with cemented endoprostheses had increased levels of activity and lower pain levels.

Keywords: hemiarthroplasty, cemented, femoral neck fracture

\section{Introduction}

Femoral neck fractures in the elderly are associated with high morbidity and mortality. ${ }^{1}$ The optimal treatment remains controversial. ${ }^{2}$ The fractures can be caused by lowenergy trauma. Hemiarthroplasty using modular head partial prostheses is a common surgical procedure used to treat elderly patients with femoral neck fractures. These prostheses can be inserted with or without bone cement. ${ }^{3}$

Hemiarthroplasty ${ }^{4}$ contributes to early ambulation and good functional recovery. However, controversy persists as to whether cemented or uncemented hemiarthroplasty is preferable for elderly patients. While femoral neck fractures treated via cemented hemiarthroplasty may be less prone to periprosthetic fracture and prosthetic loosening, they are also more likely to trigger embolisms and decreased cardiac output during
Correspondence: Fatih Karaaslan Department of Orthopedics and Traumatology, Faculty of Medicine, Bozok University, 18 Madrasa Adnan Menderes, Boulevard, Yozgat 66200, Turkey

$\mathrm{Tel}+903542127060$

Email fkaraaslan@gmail.com 
insertion of the bone cement. ${ }^{5}$ Conversely, although uncemented hemiarthroplasties are associated with higher rates of postoperative prosthesis loosening, they require shorter operation times and are associated with less intraoperative blood loss. Treatment of a displaced femoral neck fracture is currently determined by the mobility and functional demands of the patient. Cementing the prosthesis affords more secure fixation and may result in less postoperative midthigh pain and a reduced long-term revision rate (loosening is less). ${ }^{6}$

For decades, the optimal treatment choice has been debated, and whether cemented is better than uncemented hemiarthroplasty remains uncertain. Many studies have suggested that cemented hemiarthroplasty reduces the risk of residual pain and affords better functional results. ${ }^{2,7}$

A few studies found that uncemented implants yield the same clinical results as cemented implants when used to treat displaced femoral neck fractures. ${ }^{2,6,8}$ Nonetheless, the postoperative rate of prosthesis loosening is higher after uncemented hemiarthroplasty. ${ }^{6}$

The purpose of this controlled trial was to compare the results of hemiarthroplasty using a cemented ${ }^{9}$ or press-fit uncemented implant, ${ }^{10,11}$ focusing on the following three research aims: 1) Are any differences in intraoperative events detectable?; 2) Are there any differences in functional outcomes and quality of life at 1 year?; and 3) Are the rates of postoperative morbidity and mortality similar between the two groups?

\section{Methods}

\section{Demographics}

This retrospective multicenter study was performed at Osmaniye State Hospital, Bozok University Faculty of Medicine, Kayseri Training Hospital and Modern Dünyam Hospital after Bozok University Faculty of Medicine ethics committees approved the study (No 23/03). A total of 136 hip fracture patients were treated with a cemented or cementless hemiendoprostheses from 2006 to 2012. Institutional permission was granted for the use of relevant medical records and anesthetic data. During the study period, no institutional guidelines on the choice of cemented or noncemented stems were in place. The two groups exhibited similar demographics and clinical characteristics (Table 1). We reviewed the records of all patients admitted with femoral neck fractures and who died as inpatients following surgery. We recorded demographic variables, dates of admission and surgery, types of fracture, medical comorbidities, medications used, type of implant used, seniority levels of the operating surgeon and the anesthetist, hemodynamic status immediately before and after cement application and in recovery, and time and
Table I Demographics and clinical characteristics

\begin{tabular}{llll}
\hline & Range & & Mean \pm SD \\
\cline { 2 - 2 } & $\mathbf{N}$ & & $\%$ \\
\hline Age (years) & $60-110$ & $78.16 \pm 8.44$ \\
Day of surgery & $1-9$ & $2.97 \pm 1.62$ \\
Barthel score & $0-100$ & $43.80 \pm 29.12$ \\
Harris Hip Score $(n=72)$ & $40-80$ & $73.50 \pm 7.47$ \\
Mortality time (years) $(n=68)$ & $0-3$ & $0.53 \pm 0.72$ \\
\hline
\end{tabular}

Abbreviations: SD, standard deviation; $n$, sample number; $N$, total number.

cause of death. Patient age, sex, number of associated comorbidities, and prefracture ambulatory status were all retrieved. General health status was defined by the number of major comorbidities including diabetes mellitus, congestive heart failure, cardiac arrhythmias, ischemic heart disease, previous cerebrovascular accidents, renal disease, Parkinson's disease, hypertension, chronic obstructive pulmonary disease, and anticoagulation therapy. Ambulatory status was classified using the Barthel Index of Activities of Daily Living and the Harris Hip Score. Postoperative pain was assessed using the visual analog scale with responses ranging from 0 to 10 . Postoperative complications were recorded. Among them, three patients had an early revision operation, so they were excluded.

\section{Surgical procedure and rehabilitation}

Comorbidity scores derived using guidelines of the American Society of Anesthesiologists were recorded prior to surgery. The surgeon performed cemented and cementless operations using the same surgical technique: patients were placed in the lateral decubitus position and longitudinal skin incisions centered over the greater trochanter were made in the lateral position. After removing the femoral head, the hip was gently flexed, adducted, and internally rotated. The femoral canal was reamed with reamers of increasing diameter. After cortical reaming was attained, broaches were precisely placed and the fit of each broach within the canal was assessed. Adequate axial and rotational stability was assured; no motion of the broach within the canal was permitted. Next, the trial femoral stem was inserted and evaluated in terms of the responses to rotational and extraction forces. After inserting the predetermined (carefully dimensioned) femoral bipolar head, the hip was reduced and the stability of the hip joint was retested.

\section{Statistical analysis}

Statistical analysis was performed using the NCSS 2007 (NCSS, LLC, Kaysville, UT, USA) statistical software. Normality of the distribution of all parameters was tested using the Kolmogorov-Smirnov test. Parametric tests were 
used to explore differences between variables that were normally distributed, and nonparametric tests were used to explore those that were not normally distributed. Normally distributed variables were expressed as means \pm standard deviations. Student's $t$-test was used to compare normally distributed data and the Mann-Whitney $U$-test was used otherwise. The Yates continuity correction test was applied, and Pearson's correlation coefficients were calculated to examine the extent of the associations between variables. Statistical significance was defined as $P<0.05$ and $P<0.001$.

\section{Results}

The cemented and cementless groups did not differ significantly in terms of age, sex, number of major comorbidities, or prefracture ambulatory status (Table 1 ). The average age of the 67 female and 66 male patients was $78.14 \pm 8.44$ years (range: $60-110$ years) at the time of injury. The median time between injury and surgical treatment was 2.97 \pm 1.62 days. At the end of our follow-up evaluation, 68 patients had died. The mortality rate during the first year after surgery was $29.7 \%$. This fell to $15.6 \%$ in the second year, and $9.4 \%$ in the third year.
The follow-up periods of the cemented and cementless groups did not differ significantly. The mean Harris Hip Score of the group with cemented partial prostheses was $72.10 \pm 9.12$, and that of the group with cementless partial prostheses was $75.36 \pm 3.88$ points (no significant difference; $P=0.276)$. The Barthel activity and pain scores were better in the cemented group $(P=0.728)$. Thus, patients in both groups attained similarly good functional results. Of all patients, $25.6 \%$ (number $[\mathrm{n}]=34$ ) of patients were smokers and $82.7 \%$ $(n=110)$ had concurrent diseases. Of all patients, 29.3\% $(n=39)$ required intensive care, $32.3 \%(n=43)$ experienced complications, and the mortality rate was $47.1 \%(n=68)$ (Table 2). Two perioperative fat-embolic events were found in the cemented group and none in the uncemented group.

\section{Discussion}

Fractures of the proximal femur are common in the elderly. Osteoporosis, comorbidities, and increased levels of minor trauma increase the incidence and complicate the treatment of such fractures. Although cemented hemiarthroplasty has been used to treat most of these cases worldwide, noncemented prostheses are gaining popularity. Foss and

Table 2 Baseline and demographic characteristics of patients according to treatment

\begin{tabular}{|c|c|c|c|}
\hline & Cementless $(n=66)$ & Cemented $(n=67)$ & $P$ \\
\hline & Mean \pm SD (median) & Mean \pm SD (median) & \\
\hline Age (years) & $78.50 \pm 7.04$ & $77.82 \pm 9.66$ & $0.644^{\mathrm{a}}$ \\
\hline Operation day & $3.18 \pm 1.76(3.00)$ & $2.76 \pm 1.45(3.00)$ & 0.239 \\
\hline Barthel score & $43.03 \pm 29.70(40.0)$ & $44.55 \pm 28.75(40.0)$ & $0.728^{\mathrm{b}}$ \\
\hline Harris Hip Score $(n=72)$ & $75.36 \pm 3.88(76.0)$ & $72.10 \pm 9.12(76.0)$ & $0.276^{\mathrm{b}}$ \\
\hline Mortality time (years) $(n=68)$ & $0.63 \pm 0.84(0.25)$ & $0.4 \mathrm{I} \pm 0.56(0.17)$ & $0.911^{\mathrm{b}}$ \\
\hline \multirow[t]{2}{*}{ VAS score } & $3.18 \pm 1.76(3.00)$ & $2.86 \pm 1.45(3.00)$ & $0.257^{b}$ \\
\hline & n (\%) & n (\%) & \\
\hline \multicolumn{4}{|l|}{ Sex } \\
\hline Male & $31(47.0)$ & $35(52.2)$ & $0.543^{\circ}$ \\
\hline Female & $35(53.0)$ & $32(47.8)$ & \\
\hline \multicolumn{4}{|l|}{ Cigarette smokers } \\
\hline+ & $16(24.2)$ & $18(26.9)$ & $0.882^{\circ}$ \\
\hline- & $50(75.8)$ & $49(73.1)$ & \\
\hline \multicolumn{4}{|l|}{ Morbidity factors } \\
\hline+ & $54(81.8)$ & $56(83.6)$ & $0.968^{\circ}$ \\
\hline- & $12(18.2)$ & II (16.4) & \\
\hline \multicolumn{4}{|l|}{ Intensive care } \\
\hline+ & $20(30.3)$ & $19(28.4)$ & $0.955^{\circ}$ \\
\hline- & $46(69.7)$ & $48(71.6)$ & \\
\hline \multicolumn{4}{|l|}{ Complication } \\
\hline+ & $20(30.3)$ & $23(34.3)$ & $0.756^{\circ}$ \\
\hline- & $46(69.7)$ & $44(65.7)$ & \\
\hline \multicolumn{4}{|l|}{ Mortality } \\
\hline EX & $33(45.5)$ & $35(48.4)$ & $0.434^{c}$ \\
\hline Alive & $33(54.5)$ & $32(51.6)$ & \\
\hline
\end{tabular}

Notes: aStudent's t-test; 'Mann-Whitney U-test; 'Pearson's chi-squared; ‘Yates continuity correction.

Abbreviations: $n$, sample number; $S D$, standard deviation; VAS, visual analog scale; $E X$, exitus/death. 
Kehlet $^{12}$ concluded that randomized studies afforded only limited evidence that cementing the prosthesis may reduce the amount of postoperative pain and possibly improve mobility. Although serious cement-related complications have been reported, we hypothesized that, relative to cemented hemiarthroplasty, noncemented hemiarthroplasty would yield similar technical and functional outcomes and complication rates, but it would be associated with shorter operation times.

The literature abounds with early-stage success stories associated with the use of cemented bipolar hip replacements; complications are relatively few and mortality rates are low. ${ }^{13}$ Periprosthetic femoral fractures have been reported after uncemented hemiarthroplasty. Elderly and/or frail patients benefit from bone cement; this reinforces the osteoporotic proximal femur. ${ }^{13,14}$

Elmaraghy et a $1^{15}$ suggested that cemented hemiarthroplasty had no effect on the formation of fat emboli. In another study, Donaldson et $\mathrm{l}^{16}$ suggested that morbidity and mortality rates might be minimized by preferring cementless arthroplasty in high-risk patients. The reported risk of cement-related death is low but not negligible. ${ }^{17,18}$ Although some uncemented hemiarthroplasties have yielded clinical results equivalent to those of their cemented counterparts, an increased risk of subsequent fracture is evident. The risk of periprosthetic fractures may also differ between cemented femoral stems differing in design. ${ }^{19}$

Based on this theory, cementing the prosthesis could lead to higher mortality. However, the pooled results of our metaanalysis showed that perioperative mortality during fitting of a cemented prosthesis was $8.1 \%$, and it was $8.3 \%$ for an uncemented prosthesis; these prostheses were associated with 3-year mortalities of $48.4 \%$ and $45.5 \%$, respectively. Although not significant, the mortality rate was slightly higher in the cemented group. The low numbers of our cases and the shortness of follow-up times are the limitations of our study.

\section{Conclusion}

The aim of this study was to explore whether the uncemented femoral stem used in this trial would perform similarly to a cemented stem. We examined differences in Harris Hip and Barthel pain scores, femoral fractures, overall health outcomes, complications, rate of reoperation, and mortality rates.

\section{Disclosure}

The authors report no conflicts of interest in this work.

\section{References}

1. Handoll HH, Cameron ID, Mak JC, Finnegan TP. Multidisciplinary rehabilitation for older people with hip fractures. Cochrane Database Syst Rev. 2009;4:CD007125.

2. Taylor F, Wright M, Zhu M. Hemiarthroplasty of the hip with and without cement: a randomized clinical trial. J Bone Joint Surg Am. 2012;94(7): 577-583.

3. Hay M, Gottschalk F. Cemented versus uncemented hip replacement for fracture of the hip. Disabil Rehabil. 2005;27(18-19):1151-1155.

4. Bhandari M, Devereaux PJ, Tornetta P 3rd, et al. Operative management of displaced femoral neck fractures in elderly patients. An international survey. J Bone Joint Surg Am. 2005;87(9):2122-2130.

5. Parker MJ, Gurusamy K. Arthroplasties (with and without bone cement) for proximal femoral fractures in adults. Cochrane Database Syst Rev. 2006;3:CD001706.

6. Khan RJ, MacDowell A, Crossman P, et al. Cemented or uncemented hemiarthroplasty for displaced intracapsular femoral neck fractures. Int Orthop. 2002;26(4):229-232.

7. Stavrakis TA, Lyras DN, Psillakis IG, et al. Fractures of the femoral neck treated with hemiarthroplasty. A comparative study. Folia Med (Plovdiv). 2009;51(4):34-39.

8. Gjertsen JE, Lie SA, Vinje T, et al. More re-operations after uncemented than cemented hemiarthroplasty used in the treatment of displaced fractures of the femoral neck: an observational study of 11,116 hemiarthroplasties from a national register. J Bone Joint Surg Br. 2012;94(8):1113-1119.

9. Issack PS, Botero HG, Hiebert RN, et al. Sixteen-year follow-up of the cemented spectron femoral stem for hip arthroplasty. J Arthroplasty. 2003;18(7):925-930.

10. Hallan G, Lie SA, Furnes O, Engesaeter LB, Vollset SE, Havelin LI. Medium- and long-term performance of 11,516 uncemented primary femoral stems from the Norwegian arthroplasty register. $J$ Bone Joint Surg Br. 2007;89(12):1574-1580.

11. Reikerås $\mathrm{O}$, Gunderson RB. Excellent results of HA coating on a gritblasted stem: 245 patients followed for 8-12 years. Acta Orthop Scand. 2003;74(2):140-145.

12. Foss NB, Kehlet H. Mortality analysis in hip fracture patients: implications for design of future outcome trials. Br J Anaesth. 2005;94(1): 24-29.

13. Leighton RK, Schmidt AH, Collier P, Trask K. Advances in the treatment of intracapsular hip fractures in the elderly. Injury. 2007;38 Suppl 3:S24-S34.

14. Geiger F, Zimmermann-Stenzel M, Heisel C, Lehner B, Daecke W. Trochanteric fractures in the elderly: the influence of primary hip arthroplasty on 1-year mortality. Arch Orthop Trauma Surg. 2007;127(10):959-966.

15. Elmaraghy AW, Humeniuk B, Anderson GI, Schemitsch EH, Richards RR. The role of methylmethacrylate monomer in the formation and haemodynamic outcome of pulmonary fat emboli. J Bone Joint Surg Br. 1998;80(1):156-161.

16. Donaldson AJ, Thomson HE, Harper NJ, Kenny NW. Bone cement implantation syndrome. Br J Anaesth. 2009;102(1):12-22.

17. Hossain M, Andrew JG. Is there a difference in perioperative mortality between cemented and uncemented implants in hip fracture surgery? Injury. 2012;43(12):2161-2164.

18. Parvizi J, Ereth MH, Lewallen DG. Thirty-day mortality following hip arthroplasty for acute fracture. J Bone Joint Surg Am. 2004; 86-A(9):1983-1988.

19. Lindahl H, Malchau H, Herberts P, Garellick G. Periprosthetic femoral fractures classification and demographics of 1049 periprosthetic femoral fractures from the Swedish National Hip Arthroplasty Register. J Arthroplasty. 2005;20(7):857-865. 
Clinical Interventions in Aging

\section{Publish your work in this journal}

Clinical Interventions in Aging is an international, peer-reviewed journal focusing on evidence-based reports on the value or lack thereof of treatments intended to prevent or delay the onset of maladaptive correlates of aging in human beings. This journal is indexed on PubMed Central, MedLine,

CAS, Scopus and the Elsevier Bibliographic databases. The manuscript management system is completely online and includes a very quick and fair peer-review system, which is all easy to use. Visit http://www.dovepress. $\mathrm{com} /$ testimonials.php to read real quotes from published authors.

Submit your manuscript here: http://www.dovepress.com/clinical-interventions-in-aging-journal 